\title{
The Effects of Knowledge Maps on Acquisition and Retention of Visual Arts Concepts in Teacher Education
}

\author{
Paige Vitulli, Rebecca M. Giles, and Edward L. Shaw Jr. \\ Department of Leadership and Teacher Education, College of Education, University of South Alabama, UCOM 3100, Mobile, \\ AL 36608, USA \\ Correspondence should be addressed to Paige Vitulli; pvitulli@southalabama.edu
}

Received 22 January 2014; Revised 19 May 2014; Accepted 20 May 2014; Published 16 June 2014

Academic Editor: Jan Elen

Copyright (C) 2014 Paige Vitulli et al. This is an open access article distributed under the Creative Commons Attribution License, which permits unrestricted use, distribution, and reproduction in any medium, provided the original work is properly cited.

\begin{abstract}
This study examined the use of knowledge maps as a tool for teacher education students to increase knowledge acquisition and retention of concepts related to the visual arts design elements: line, color, and shape. Participants were randomly assigned to either the no map or knowledge map group. Three instruments-Student Autobiography, Elements of Design Tests (EDT), and Knowledge Map Questionnaire-were used to collect data. Results revealed significantly higher means on the immediately administered posttest for the elements line and color and the delayed posttest for line map group. Questionnaire responses indicated positive attitudes toward knowledge map use as a study strategy. Specifically, endorsement was reported toward maps' clarity, effectiveness for learning concepts, and enjoyment of use.
\end{abstract}

\section{Introduction}

Recent years have seen the adoption of a standards-based approach to education within the United States $[1,2]$ and abroad [3]. "As the American Recovery and Reinvestment Act of 2009 was used to stimulate the economy, the Obama Administration employed the Race to the Top fund to encourage states to apply for grants to pursue reforms by adopting standards and assessments that prepare students to succeed in college and the workplace and compete in the global economy...." [4, p. 92]. Within the current sociopolitical climate of standards-based education reform, the escalating emphasis for learning outcomes and meeting standards in an increasingly information overloaded context is not likely to diminish.

From kindergarten to higher education, increasing amounts of time and resources are being committed to assessment and documentation of outcomes that meet local, state, and national criteria or standards. As educators and students strive to facilitate and utilize efficient and effective teaching and learning strategies in an increasingly outcomesaccountable environment, they are also discovering that, in the realm of overwhelming information access, the current methods used to create meaning may need to be reexamined.
The variety and fluidity of contexts in which teachers and learners operate necessitate solid subject matter knowledge as well as vast pedagogical knowledge; educators, like learners, must also make connections between ideas and integrate their knowledge in order to achieve meaningful learning [5]. Bransford et al. [6] asserted that "there is no universal best teaching practice," (page 22) since teaching strategies are mediated by numerous variables including the learner, course, subject matter, and desired outcome. Yet according to McDonald et al. [7], "determining what works best, for whom, and under what conditions are the central tasks that educational researchers are being asked to address" (page 15). New strategies, methods, or tools and the use of existing strategies, methods, or tools in new ways, with diverse learners and in varied contexts, should be continuously examined to validate the effectiveness of current practices. Concept mapping $[8,9]$ is a knowledge representation technique commonly used by teachers and students at all levels that holds vast potential in regard to its effectiveness as a teaching and learning strategy.

\section{Concept Mapping}

The concept map and concept mapping technique were developed by Novak [8-10] at Cornell University in the 1960s. 


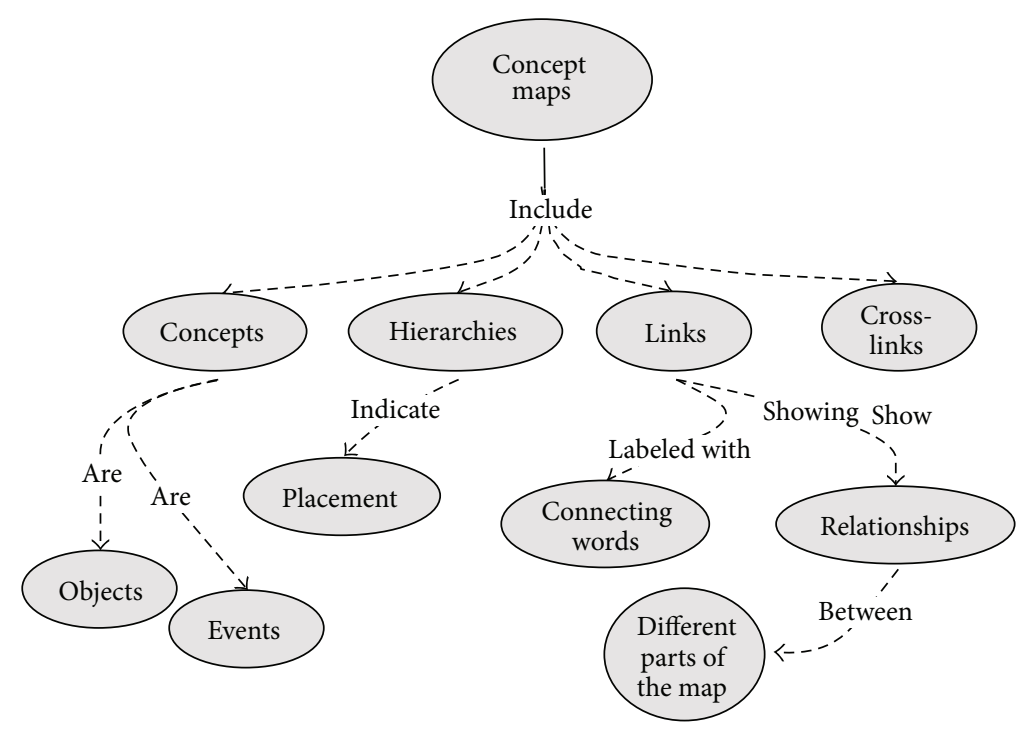

FIGURE 1: Example of a concept map.

Novak's work was based on the theories of Ausubel [11-13], who emphasized prior knowledge as a key to one's ability to learn new concepts. Novak [9] claimed that meaningful learning involved the assimilation of new concepts into existing cognitive structures. Concept mapping visually represents concepts and the complex relationships among the concepts. Concepts are enclosed in nodes, typically depicted by words enclosed in circles, ovals, or rectangles. The relationships among the concepts are represented by a link or line with an arrow to connect multiple concepts. Figure 1 is an example of a concept map.

Alternative versions of this graphic organizer have been identified as webs [14] and mind maps [15]. Anderson and Milbrandt [14] found that many teachers used webbing during group discussions as a theme introduction and brainstorming exercise. The construction of associations through a web helped students brainstorm ideas and visualize connections of concepts. Moline [16] described web diagrams as summarization of the process of an integrated network of relationships, rather than a process that moves in one direction such as a cyclical diagram. Moline also indicated that webs were diagrams that linked their subjects with a network of lines or arrows and included concept mapping as a subset of webbing where meaningful connections are made between concepts.

Mind mapping, which appears to a great extent in international literature, was invented (and copyrighted) by Buzan [15] from the United Kingdom. Buzan describes mind maps as colorful, spatial, learning tools consisting of a central word or concept, around which main ideas that relate to that word are represented. Each of the main ideas is considered and subideas that relate to each of those words are represented using images, numbers, color, and spatial awareness in addition to words. Although it is important to point out that the literature represented overlapping and inconsistent representations of characteristics, the originators noted primary differences between Buzan's [15] mind maps and Novak's [8,9] concept maps. A mind map generally contains one main concept, while a concept map may have several main concepts. The mind map structure is tree-like, branching out from a single, central idea, while concept maps tend to be complex networks. While a concept map typically is not generated in varied colors and usually includes words only, mind mapping utilizes three or more colors and various images, along with words. "It [mind map] harnesses the full range of cortical skills-word, image, number, logic, rhythm, color, and spatial awareness - in a single, uniquely powerful manner" [17, p. 7]. Mind maps have been used successfully with students at various levels as a means of representing knowledge and facilitating meaningful learning for many years [18] and gained recent credibility in corporations such as Paxman [17].

Concept mapping, as a tool to visualize and communicate conceptual understanding, has been extensively utilized in classroom teaching [19] and is widely accepted as one of several tools valid for measuring conceptual change [20]. According to O'Donnell et al. [21], concept maps serve as supports or scaffolds to cognitive processing, reduce cognitive load, and enhance representation of relationships among constructs. The literature revealed studies of concept maps most often applied to the teaching and learning of science concepts [22-28] and, to a lesser amount, math [29, 30]. Novak [10] reflected on his own twelve-year longitudinal study on children's science concept learning, claiming that
"There is now general agreement that knowledge is a human creation, where new ideas are con- structed by creative people on the basis of their existing concepts and theories and of a search for new patterns or regularities in events or objects, or records of events or objects, designated by a label, usually a word" (page 23).

Knowledge maps, which also represent ideas or concepts contained in nodes with the relationships among these 
identified through links, differ from concept maps, according to O'Donnell et al. [21], in that the links used to connect ideas are labeled to facilitate cognitive processing. In addition, knowledge maps are described as teacher or expert generated for the purpose of providing an alternative or additive source of information during instruction. Creation of a knowledge map to represent a topic can be a beneficial process for teachers as well as students since creating one's own maps allows important content to be articulated and relationships to be displayed from the instructor's perspective, possibly resulting in clearer communication of goals and improved learning [21].

Lee and Nelson [31] define a concept map as that which the learner develops as an instructional strategy, while a knowledge map, which is generated by the teacher or expert for the learner to view, is considered an instructional material. The literature includes articles, papers, and studies [32-34] that explored the effects of learner-generated concept maps and teacher-generated knowledge maps. Significant interest among educational researchers in the use of mapping as an instructional aid over the last 30 years led O'Donnell et al. [21] to conclude that "the fit of knowledge maps to various kinds of knowledge structures and combinations of structures is worthy of further study" (page 75).

In [35], Nesbit and Adesope estimated that more than 500 peer-reviewed articles, most published since 1997, have made substantial reference to the educational application of concept or knowledge maps. Few, if any, empirical studies, however, have explored the effects of concept mapping, mind mapping, or knowledge maps as an instructional strategy or material for visual arts content. The elements of designline, shape, color, form, space, color, value, and texture-are a common thread of introductory visual arts instruction, which construct the basic language or building blocks of visual arts.

De Simone [36] cited increasing awareness that college and university students, who are often assumed to be proficient at understanding and applying information gained from text, actually have difficulty abstracting important points, relating ideas, and organizing concepts. One possible factor contributing to this difficulty could be lack of prior knowledge related to the knowledge domain. This study explicitly explored the role of knowledge maps as a tool for teacher education students to increase knowledge acquisition and retention of visual arts content, which is traditionally novel information for this population. Specifically, the effect of text only as compared to text with knowledge map viewing on the knowledge acquisition and retention of the visual art elements, line, shape, and color, and attitudes regarding knowledge maps as an instructional material in teacher education were investigated.

\section{Method}

3.1. Participants. Data were collected from 78 individuals enrolled in 3 undergraduate and 1 graduate elementary education courses at a college of education in a southeastern university. Of the 78 participants, 4 were men. The ethnicity of the participants was 18 African-American, 59 Caucasian, and one Hispanic. Most participants $(n=70)$ were aged 35 or under. Through random assignment, 41 of the participants were assigned to the no map group and 39 were assigned to the map group. The no map group participants reported a GPA mean of 3.4, while the 37 who received the knowledge map as a study strategy had a self-report GPA that averaged 3.5.

3.2. Instruments. Two instruments, Elements of Design Tests and Knowledge Map Questionnaire, were used for collecting data. The Elements of Design Delayed Posttest (see Appendix A) is a 75-item multiple-choice test, which yields a separate score for each of its three subtests-line, shape, and color. Each subtest score is calculated by determining the number of correct responses for its 25 items (line: items 125, shape: items 26-50, and color: items 51-75). The highest possible score on each subtest is 25 .

Using the Elements and Principles of Design Student Guide [37], which served as a content resource for participants, 115 possible test questions related to line, shape, and color were generated and evaluated by three experts (two art educators and a museum curator), who individually rated each item's representation of content. The 25 items for each of the 3 elements that received the highest average scores comprised the 75-item multiple choice Elements of Design Delayed Posttest (EDDP), which yields a separate score for each of its 3 subtests-line, shape, and color. The format, instructions, and vocabulary were further evaluated resulting in final adjustments to eliminate ambiguity and increase clarity. One point is awarded for each correct response resulting in a possible high score on each subtest of 25 , with the highest possible total score being 75 . Test-retest reliability for the EDDP was obtained from a sample of 20 students who took the test twice with a 7-day interval between test administrations. Pearson $r$ correlations for all three subtests using Bonferroni to control for Type I error showed that 19 out of the 20 correlations were statistically significant at the .0025 level. Each 25-item subtest of the EDDP served as the posttest for the elements line, shape, and color.

\section{Knowledge Map Questionnaire}

The Knowledge Map Questionnaire (see Appendix B) was designed by the researchers to ascertain the participants' attitudes toward viewing knowledge maps as a study strategy and consists of six questions designed to ascertain participants' attitudes toward viewing knowledge maps as a study strategy. Specifically 3 areas: clarity of maps, effectiveness for learning, and enjoyment in use are each assessed by two alternately worded items. The three areas are each assessed by two alternately worded questions as follows: clarity of maps (items 1 and 4), effectiveness for learning (items 2 and 6), and enjoyment in use (items 3 and 5). Participants respond using a five-point rating scale ranging from strongly agree (4) to strongly disagree (1) and not sure (0). Quantitative numerals assigned for data analysis are four through zero with reversely worded items (four, five, and six) being reverse scored to consistently assign the highest numerals to the most 
positive attitudes toward viewing the knowledge maps. The questionnaire also contains a section for participants' openended comments.

\section{Procedure}

The research design was a posttest-only control group design eliminating threats to internal validity (i.e., testing threat) that taking the pretest could have caused. Prior to beginning this study, separate knowledge maps for the design elements, line, shape, and color, as depicted in the Elements and Principles of Design Student Guide [37], were created and reviewed by a team of teacher educators and educational researchers.

On the first day of class, participants were randomly assigned to one of two groups using a random numbers table. Forty-one of the participants were assigned to the no map group, while 37 received the knowledge map as a study strategy. Two participants from the map group were eliminated from the study due to class absences. Group 1: no map was the control group, and Group 2: knowledge map was the treatment group. The treatment occurred over three consecutive class meetings.

On the first day of treatment, Group 1 was given the Elements and Principles of Design: Student Guide and instructed to read and view the content on the element of line (pages 4-5) for 20 minutes. Group 2 was given the Elements and Principles of Design: Student Guide [37] and the knowledge map for the element of line. Group 2 was instructed to read and view the content on the element of line in the guide and view the knowledge map for 20 minutes. After 20 minutes to independently attend to the material, the Elements of Design Posttest: Line was administered. In order to avoid a history effect (events other than the planned treatment to occur and influence the postmeasurement) the posttest was given immediately after the treatment. On days two and three, the same procedure was followed with the varied content of the design elements of shape (pages 6-7) and color (pages 10-11), respectively. Elements of Design Posttest: Shape was administered on day two; and Elements of Design Posttest: Color was administered on day three. The Elements of Design Delayed Posttest was administered four days after the last treatment and final posttest to assess knowledge retention.

\section{Data Analysis}

Data analysis was conducted using the statistical package for the social sciences (SPSS) to analyze scores from the three Elements of Design Posttests and the Elements of Design Delayed Posttest using analyses of variance (ANOVA) to evaluate the relationship between viewing knowledge maps and knowledge acquisition and retention of the elements of design: line, shape, and color. The independent variable, knowledge map factor, included two levels: viewing the text and knowledge map (knowledge map) and viewing text only (no map). The dependent variable for knowledge acquisition was scores on the three Elements of Design Posttests, and the dependent variable for knowledge retention was scores on the
TABLE 1: Means, standard deviations, and ANOVAs for immediate assessment of knowledge map strategy.

\begin{tabular}{lcccccc}
\hline Design element & $\mathrm{M}$ & $\mathrm{SD}$ & $\mathrm{df}$ & $F$ & $\eta^{2}$ & $P$ \\
\hline Line & & & 1 & 4.70 & .06 & .03 \\
$\quad$ No map & 19.78 & 3.54 & & & & \\
$\quad$ Map & 21.38 & 2.89 & & & & \\
Shape & & & 1 & .01 & .00 & .93 \\
$\quad$ No map & 19.44 & 3.76 & & & & \\
$\quad$ Map & 19.51 & 3.25 & & & & \\
Color & & & 1 & 9.83 & .12 & .00 \\
$\quad$ No map & 17.27 & 4.64 & & & & \\
$\quad$ Map & 20.22 & 3.52 & & & & \\
\hline
\end{tabular}

Elements of Design Delayed Posttest. Additionally, frequencies and percentages were calculated for the Knowledge Map Questionnaire responses to ascertain participant attitudes toward viewing the knowledge map as a study strategy.

\section{Results}

Overall ANOVA results of the immediate administration of the posttest, as shown in Table 1 , revealed significant differences between the map and no map groups for the elements of line, $F(1,76)=4.71, P=.033$, and color, $F(1,76)=9.833, P=.002$, indicating that the knowledge map could be attributed to increased art element of design knowledge acquisition. But it was of interest that the mean posttest scores for the element of shape did not reveal significantly higher means, $F(1,76)=.009, P=.926$, for the knowledge map group. One explanation may be related to the differences among the elements tested. The content representing the element of shape is inherently less complex. Upon an analysis of the differences among the knowledge maps, the concept of shape included the least number of nodes and propositions, whereas line and color knowledge maps were denser. Furthermore, the element of color, for which the knowledge map included the greatest number of nodes and propositions, also had the greatest mean difference scores, indicating that the number of concepts might have been a variable related to the usefulness of the knowledge map for knowledge acquisition. Another consideration is that participants' prior knowledge could have been greater for the concepts related to shape as these concepts overlap with content covered in other realms such as mathematics classes.

As with the immediate knowledge retention measurement, Table 2 shows the Elements of Design Delayed Posttest means were higher among the group that viewed the knowledge map for each of the three design elements. As expected, the mean differences were less between each Elements of Design Posttest for the delayed measure as compared to the immediate measure. The posttest mean scores for the two groups were not statistically significantly different for shape, $F(1,76)=.179, P=.673$, and color, $F(1,76)=.396$, $P=.53$. The delayed posttest means for the knowledge map group for line were statistically significant, $F(1,76)=4.95$, $P=.03$. Participants were not informed ahead of time that 
TABle 2: Means, standard deviations, and ANOVAs for delayed assessment of knowledge map strategy.

\begin{tabular}{lcccccc}
\hline Design element & $\mathrm{M}$ & $\mathrm{SD}$ & $\mathrm{df}$ & $F$ & $\eta^{2}$ & $P$ \\
\hline Line & & & 1 & 4.95 & .06 & .03 \\
$\quad$ No map & 18.85 & 4.13 & & & & \\
$\quad$ Map & 20.62 & 2.65 & & & & \\
Shape & & & 1 & .18 & & .67 \\
$\quad$ No map & 18.15 & 4.38 & & & & \\
$\quad$ Map & 18.54 & 3.78 & & & \\
Color & & & 1 & .40 & & .53 \\
$\quad$ No map & 18.63 & 4.89 & & & & \\
$\quad$ Map & 19.30 & 4.36 & & & & \\
\hline
\end{tabular}

a delayed posttest would be administered, but a history effect (practice of taking previous tests with similar questions) may have contributed to an increase in the mean scores for the delayed measure.

As shown in Table 3, the vast majority of responses on the Knowledge Map Questionnaire indicated positive attitudes were associated with the participants' perceptions of knowledge map use as a study strategy. Specifically, endorsement in the following areas through agreement with positive statements and disagreement with negative statements regarding map use was reported: clarity of maps (95\%), effectiveness for learning concepts (90\%), and enjoyment of using maps (97\%). In addition, 20 of the 37 respondents wrote additional comments. Overall, 18 of the comments were positive with 2 expressing negative attitudes. The positive comments indicated that the knowledge maps provided summarization and organization and facilitated learning the concepts. Two participants referred to the benefits of visual learning, while one expressed that the maps enabled the participant "to see how things connected to each other." In contrast, two participants expressed that the maps were confusing. One said "Some lines crossed and were hard to follow" and the other expressed that "computer generated knowledge maps are often broken down too far and are confusing."

\section{Discussion}

According to Driscoll [38], graphic organizers and imagery are strategies that facilitate information processing and connecting prior knowledge with new information. Previous research $[25-28,39,40]$ indicated that utilization of various forms of concept mapping may lead to increased learning. In this study, which explored results of the cognitive processing of the participants as they interacted with text and knowledge maps, there was not a condition where viewing knowledge maps produced significant negative effects and the attitudes toward the strategy were generally positive, thus, indicating that teachers should consider knowledge maps as a viable learning strategy to facilitate the acquisition of concepts. Further, the results are intended to provide a footing for future teaching and learning practices among teacher educators and preservice and inservice teachers and a basis for future knowledge mapping research in various modalities and contexts.

While a single study cannot provide conclusive evidence that a particular teaching method ensures knowledge acquisition and/or retention, the literature on concept mapping was extended based on the results of this experiment. The findings suggest providing knowledge maps may be a viable educational practice for helping students efficiently acquire the basic concepts of art from which higher-level activities can be built. The consideration that initiating a new teaching method should occur over an extended period of time and that outcomes should be evaluated in varied contexts is emphasized by the lack of significance among all art elements of design tested. Further, as suggested by other studies [41, 42], participants' learning may have been more positively influenced by the use of learner-generated rather than expertgenerated maps.

A repeat of the study during a traditional semester and with an increased number of participants may provide greater insight into the effect the treatment may have had on knowledge acquisition and retention. It was determined that, due to limited time for training and practicing, generative concept mapping skills would reduce the effectiveness of this experimental treatment in the study. It could not be assumed that participants would be well prepared in mapping strategies. Novak [9] indicated that successful generation of concept maps requires practice and a considerable amount of trial and error. Further research should include studentgenerated maps with analysis of the map generation to provide a more in-depth assessment and analysis of the participants' knowledge. Additionally, the students' attitudes toward creating their own maps in comparison to being provided a knowledge map would be of interest.

As a result of informal observation during the data collection, varied approaches to attending to the learning materials were noted. An analysis of participant learning styles and the correlation with knowledge acquisition and retention might provide interesting results. Finally, knowledge and concept map research should be extended to assess learning outcomes beyond immediate and delayed knowledge acquisition or recall, including higher-level learning such as application, analysis, and synthesis.

\section{Appendices}

\section{A. Elements of Design Delayed Posttest (EDDP)}

Name:

(1) A line can vary in
(a) length and width
(b) direction
(c) curvature
(d) all of the above 
TABLE 3: Frequencies of responses measuring attitudes.

\begin{tabular}{|c|c|c|c|c|c|}
\hline Attitude statement & Strongly agree & Agree & Disagree & Strongly disagree & Not sure \\
\hline \multicolumn{6}{|l|}{ Clarity of maps } \\
\hline (1) Maps were easy to understand. & 22 & 13 & 2 & 0 & 0 \\
\hline (4) Viewing maps confused me. & 0 & 0 & 19 & 18 & 0 \\
\hline \multicolumn{6}{|l|}{ Effectiveness for Learning } \\
\hline (2) Maps helped me learn the concepts. & 22 & 15 & 0 & 0 & 0 \\
\hline (5) Maps had no effect on my learning of the concepts. & 1 & 1 & 14 & 19 & 2 \\
\hline \multicolumn{6}{|l|}{ Enjoyment } \\
\hline (3) I enjoyed viewing the maps. & 14 & 22 & 1 & 0 & 0 \\
\hline (6) I did not like the maps. & 0 & 1 & 16 & 20 & 0 \\
\hline
\end{tabular}

(2) A line can only be
(a) straight
(b) two-dimensional
(c) black
(d) all of the above

(3) A mark with length and direction, created by a point that moves across a surface is
(a) rhythm
(b) line
(c) movement
(d) value

(4) is a mark made by a moving point
(a) Rhythm
(b) Line
(c) Movement
(d) Value

(5) A line stands straight up at a right angle to the horizon.
(a) diagonal
(b) vertical
(c) horizontal
(d) zig zag

(6) Lines that are made from a combination of diagonal lines that form angles and change direction suddenly are called lines.
(a) diagonal
(b) vertical
(c) horizontal
(d) zig zag

(7) A _-_-_-_line slants and appears to be rising or falling.
(a) diagonal

(b) vertical

(c) horizontal

(d) zig zag

(8) A line changes direction gradually.
(a) curving
(b) vertical
(c) horizontal
(d) zig zag

(9) A to the horizon line.
(a) curving
(b) vertical
(c) horizontal
(d) zig zag

(10) Lines can be combined with other lines to create
(a) textures
(b) patterns
(c) shapes
(d) all of the above

(11) lines suggests a feeling of rest or repose.
(a) Wavy
(b) Horizontal
(c) Vertical
(d) Diagonal

(12) ___ in combination communicate stability and solidity.
(a) Horizontal and vertical lines
(b) Shallow and acute curves
(c) Diagonal and wavy lines
(d) Wavy and zig zag lines 
(13) ___ indicate edges of forms or shapes and describe them in the simplest way.
(a) Gestural lines
(b) Implied lines
(c) Contour lines
(d) Organic lines

(14) _------_ indicate action and physical movement.
(a) Gestural lines
(b) Implied lines
(c) Contour lines
(d) Organic lines

(15) When our eyes "read" the edges of objects this is referred to as
(a) gestural lines
(b) implied lines
(c) contour lines
(d) organic lines

(16) Closely drawn lines in more than one direction are referred to as
(a) cross-hatched
(b) gesture
(c) meandering
(d) radiating

(17) Contour lines are
(a) many rapidly drawn lines
(b) closely drawn lines in more than one direction
(c) the outline of a subject with a single line
(d) lines that are not actually drawn, but "read" by the eyes

(18) Gesture lines are

(a) many rapidly drawn lines

(b) closely drawn lines in more than one direction

(c) the outline of a subject with a single line

(d) lines that are not actually drawn, but "read" by the eyes

(19) Implied lines are

(a) many rapidly drawn lines

(b) closely drawn lines in more than one direction

(c) the outline of a subject with a single line

(d) lines that are not actually drawn, but "read" by the eyes

(20) The element of line

(a) is a mark made by a pointed tool. (b) is often defined as a moving dot.

(c) has length and width, but its width is very tiny compared to its length.

(d) (a), (b) and (c)

(21) The three basic properties of line are

(a) direction, measure, and character

(b) color, texture, and value

(c) organic, geometric, and gestural

(d) continuous, converging, and criss-cross

(22) Direction, measure, and character are

(a) defined as a moving dot

(b) many rapidly drawn lines

(c) the basic properties of line

(d) (a), (b) and (c)

(23) The basic property of line that shows emotional qualities and is greatly dependent on the nature of the artistic media that the artist uses is called
(a) the direction of line
(b) the measure of line
(c) the character of line
(d) all of the above

(24) The basic property of line that reveals an infinite number of combinations of long and short, thick and thin lines within a composition is
(a) the direction of line
(b) the measure of line
(c) the character of line
(d) all of the above

(25) The basic property of line that is described as horizontal, diagonal and/or vertical is
(a) the direction of line
(b) the measure of line
(c) the character of line
(d) all of the above

(26) A shape has
(a) three dimensions, length, width and depth
(b) two dimensions, length and width
(c) two dimensions, length and depth
(d) two dimensions, width and depth

(27) Design in painting is basically the planned arrangement of
(a) color
(b) line 

(c) texture
(d) shape

(28) Abstract shapes
(a) may be based on reality
(b) are realistic
(c) can be the dominant element in a composition
(d) (a) and (c)

(29) Amorphous shapes
(a) are triangles, rectangles, squares, circles, ovals
(b) are the areas surrounding the main form
(c) lack definite form such as clouds
(d) (b) and (c)

(30) Geometric shapes
(a) are triangles, rectangles, squares, circles, ovals
(b) are the areas surrounding the main form
(c) lack definite form such as clouds
(d) (b) and (c)

(31) Positive shape
(a) is the main form of a composition
(b) is the area surrounding the main form
(c) is always geometric
(d) is always asymmetrical

(32) Negative shape
(a) is the main form of a composition
(b) is the area surrounding the main form
(c) is always geometric
(d) is always asymmetrical

(33) Geometric shapes are also called
(a) curvilinear shapes
(b) positive shapes
(c) negative shapes
(d) rectilinear shapes

(34) Organic shapes are also called
(a) curvilinear shapes
(b) positive shapes
(c) negative shapes
(d) rectilinear shapes

(35) The subject in representational work is usually the shape.
(a) curvilinear shape
(b) positive shape

(c) negative shape

(d) rectilinear shape

(36) Shapes in nature are usually shapes.
(a) curvilinear shapes
(b) geometric shapes
(c) organic shapes
(d) rectilinear shapes

(37) ---------- often reduces things to their simplest shapes.
(a) Collage
(b) Pattern
(c) Abstraction
(d) Representation

(38) Shapes that are irregular and asymmetrical are also called shapes.
(a) geometric
(b) free-form
(c) negative
(d) positive

(39) Living organisms such as animals, fish, and flowers are shapes.
(a) geometric
(b) biomorphic
(c) negative
(d) positive

(40) All shapes can be described with two basic terms and
(a) geometric and organic
(b) biomorphic and organic
(c) geometric and rectilinear
(d) organic and curvilinear

(41) Shapes are either or
(a) positive or negative
(b) biomorphic or organic
(c) geometric or rectilinear
(d) organic or curvilinear

(42) In abstract or nonobjective art, usually central or featured elements. shapes are
(a) organic
(b) biomorphic
(c) negative
(d) positive 
(43) Most of Picasso's shapes are
(a) representational
(b) realistic
(c) flat
(d) three-dimensional

(44) Shape is seen or identified because of
(a) color changes
(b) value changes
(c) implied lines
(d) (a), (b), and (c)

(45) The area around the subject in a representational work is usually the
(a) positive shape
(b) negative shape
(c) dark shape
(d) light shape

(46) The main form of a composition is called
(a) positive shape
(b) negative shape
(c) dark shape
(d) light shape

(47) The area surrounding the main form of a composition is called
(a) positive shape
(b) negative shape
(c) dark shape
(d) light shape

(48) shapes. shapes appear stronger than
(a) Geometric; biomorphic
(b) Biomorphic; geometric
(c) Geometric; rectilinear
(d) Organic; curvilinear

(49) Organic shapes have curved edges and are often called
(a) free-form
(b) rectilinear
(c) geometric
(d) negative

(50) When artists use both types of shapes in a drawing or painting, one type of shape is usually
(a) red
(b) dominant

(c) flat

(d) representational

(51) Color depends on light because
(a) it is made of light
(b) it is a product of light
(c) (a) and (b)
(d) none of the above

(52) The chart used to remember color relationships is a
(a) color scheme
(b) color wheel
(c) color ray
(d) color circle

(53) Secondary colors are obtained by mixing two
(a) neutral colors
(b) complementary colors
(c) primary colors
(d) intermediate or tertiary colors is another term for color.

(54)
(a) Tone
(b) Hue
(c) Value
(d) Intensity

(55) Red and green are examples of
(a) intermediate colors
(b) analogous colors
(c) color triad
(d) complementary colors

(56) Colors are said to be contrasting if they are
(a) different in lightness and darkness
(b) light in value
(c) dark in value
(d) bright and intense

(57) are examples of cool colors.
(a) Orange, green and purple (or violet)
(b) Blue, green and violet (or purple)
(c) Yellow, blue and red
(d) White, black and brown

(58) are examples of warm colors.

(a) Yellow, to red-violet 
(b) Yellow, red, and blue

(c) Yellow-green to violet

(d) Orange, purple, and green

(59) Yellow-orange, red-orange, and yellow-green are
(a) intermediate or tertiary colors
(b) secondary colors
(c) primary colors
(d) triadic colors

(60) Blue and orange are
(a) primary colors
(b) related or analogous colors
(c) secondary colors
(d) complementary colors

(61) Orange, green, and violet (or purple) are
(a) primary colors
(b) related or analogous colors
(c) secondary colors
(d) complementary colors

(62) Red, yellow, and blue are
(a) primary triad
(b) related or analogous colors
(c) secondary colors
(d) complementary colors

(63) Yellow, yellow-orange, orange are
(a) primary triad
(b) related or analogous colors
(c) secondary colors
(d) complementary colors

(64) A related color scheme would be colors that are
(a) across form each other on the color wheel
(b) next to each other on the color wheel.
(c) all primary
(d) all secondary colors

(65) may be created by adding white.
(a) Value
(b) Shade

(c) Hue

(d) Tint

(66) Another word for lightness or darkness of a color is
(a) value
(b) intensity
(c) hue
(d) complementary

(67) ---------_-_are made by mixing equal parts of two primary colors.
(a) Intermediate or tertiary colors
(b) Analogous colors
(c) Secondary colors
(d) Complementary colors

(68) Colors that are across from each other on the color wheel are known as
(a) intermediate or tertiary colors
(b) analogous colors
(c) a color triad
(d) complementary colors

(69) Three colors that are equal distance apart on the color wheel are
(a) intermediate or tertiary colors
(b) analogous colors
(c) a color triad
(d) complementary colors

(70) Colors that are next to each other on the color wheel are
(a) intermediate or tertiary colors
(b) analogous colors
(c) a color triad
(d) complementary colors

(71) Colors obtained by mixing secondary colors and primary colors are
(a) intermediate or tertiary colors
(b) analogous colors
(c) a color triad
(d) complementary colors

(72) A band of colors produced when white light shines through a prism
(a) shows primary colors
(b) shows secondary colors 
(c) contains only neutrals

(d) is a color spectrum

(73) The three basic colors that cannot be made by mixing colors are
(a) primary colors
(b) secondary colors
(c) neutrals
(d) color spectrum

(74) Colors that appear to recede are known as
(a) warm
(b) cool
(c) primary
(d) secondary

(75) Colors that appear to advance are known as
(a) warm
(b) cool
(c) primary
(d) secondary.

\section{B. Knowledge Map Questionnaire}

Please read each of the following statements carefully.

Circle the answer that best reflects how you feel.

(1) Knowledge maps were easy to understand

Strongly Agree
Agree
Disagree
Strongly Disagree
Not Sure

(2) The knowledge maps helped me learn the concepts

Strongly Agree
Agree
Disagree
Strongly Disagree
Not Sure

(3) I enjoyed viewing the knowledge map
Strongly Agree
Agree
Disagree
Strongly Disagree
Not Sure

(4) Viewing the knowledge maps confused me

Strongly Agree
Agree
Disagree
Strongly Disagree
Not Sure

(5) I did not like viewing the knowledge map

Strongly Agree
Agree
Disagree
Strongly Disagree
Not Sure

(6) The knowledge maps had no effect on my learning of the concepts

$$
\begin{aligned}
& \text { Strongly Agree } \\
& \text { Agree } \\
& \text { Disagree } \\
& \text { Strongly Disagree } \\
& \text { Not Sure. }
\end{aligned}
$$

Additional comments on viewing the knowledge map.

\section{Conflict of Interests}

The authors declare that there is no conflict of interests regarding the publication of this paper.

\section{References}

[1] J. R. Altman, S. S. Lazarus, R. F. Quenemoen, J. Kearns, M. Quenemoen, and M. L. Thurlow, Survey of States: Accomplishments and New Issues at the End of a New Decade of Change, National Center on Educational Outcomes, University of Minnesota, Minneapolis, Minn, USA, 2009.

[2] L. Llosa, "Standards-based classroom assessments of English proficiency: a review of issues, current developments, and future directions for research," Language Testing, vol. 28, no. 3, pp. 367382, 2011.

[3] D. Mulcahy, "Assembling the "accomplished" teacher: the performativity and politics of professional teaching standards," Educational Philosophy and Theory, vol. 43, no. 1, pp. 94-113, 2011.

[4] M. G. Watt, "The common core state standards initiative: an overview," 2011, http://www.eric.ed.gov/contentdelivery/servlet/ERICServlet?accno=ED522271.

[5] E. Davis and J. Krajcik, "Designing educative curriculum materials to promote teacher learning," Educational Researcher, vol. 34, no. 3, pp. 3-14, 2005.

[6] J. Bransford, A. Brown, and R. Cocking, Eds., How People Learn: Brain, Mind, Experience and School, Commission on Behavioral and Social Sciences and Education, National Research Council, National Academy Press, Washington, DC, USA, 2000. 
[7] S. McDonald, V. Keesler, C. Kauffman, and B. Schneider, "Scaling-up exemplary interventions," Educational Researcher, vol. 35 , no. 3, pp. 15-24, 2006.

[8] J. D. Novak, A Theory of Education, Cornell University Press, Ithaca, NY, USA, 1977.

[9] J. D. Novak, Learning, Creating, and Using Knowledge: Concept Maps As Facilitative Tools in Schools and Corporations, Erlbaum, Mahwah, NJ, USA, 1998.

[10] J. D. Novak, "Reflections on a half-century of thinking in science education and research: implications from a twelve-year longitudinal study of children's learning," The Canadian Journal of Science, Mathematics and Technology Education, vol. 4, no. 1, pp. 23-41, 2004.

[11] D. P. Ausubel, The Psychology of Meaningful Verbal Learning, Grune \& Stratton, New York, NY, USA, 1963.

[12] D. P. Ausubel, Educational Psychology: A Cognitive View, Holt, Rinehart \& Winston, New York, NY, USA, 1968.

[13] D. P. Ausubel, "A cognitive theory of school learning," Psychology in the Schools, vol. 6, pp. 331-335, 1969.

[14] T. Anderson and M. Milbrandt, Art for Life: Authentic Instruction in Art, McGraw-Hill, New York, NY, USA, 2002.

[15] T. Buzan, The Mind Map Book: How to Use Radiant Thinking to Maximize Your Brain's Untapped Potential, Penguin, New York, NY, USA, 1993.

[16] S. Moline, I See What You Mean: Children at Work with Visual Information, Black Cockatoo, Melbourne, Australia, 1995.

[17] C. G. Paxman, "Map your way to speech success! Employing mind mapping as a speech preparation technique," Communication Teacher, vol. 25, no. 1, pp. 7-11, 2011.

[18] C. Howitt, "3-D mind maps: placing young children in the centre of their learning," Teaching Science, vol. 55, no. 2, pp. 4246, 2009.

[19] G. R. Mackinnon and M. Keppell, "Concept mapping: a unique means for negotiating meaning in professional studies," Journal of Educational Multimedia and Hypermedia, vol. 14, pp. 291-315, 2005.

[20] K. J. Miller, K. A. Koury, G. E. Fitzgerald et al., "Concept mapping as a research tool to evaluate conceptual change related to instructional methods," Teacher Education and Special Education, vol. 32, no. 4, pp. 365-378, 2009.

[21] A. M. O'Donnell, D. F. Dansereau, and R. H. Hall, "Knowledge maps as scaffolds for cognitive processing," Educational Psychology Review, vol. 14, no. 1, pp. 71-86, 2002.

[22] D. Luckie, S. H. Harrison, and D. Ebert-May, "Model-based reasoning: using visual tools to reveal student learning," American Journal of Physiology: Advances in Physiology Education, vol. 35, no. 1, pp. 59-67, 2011.

[23] S. Gerstner and F. X. Bogner, "Concept map structure, gender and teaching methods: an investigation of students' science learning," Educational Research, vol. 51, no. 4, pp. 425-438, 2009.

[24] S. Boujaoude and M. Attieh, "The effect of using concept maps as study tools on achievement in chemistry," Eurasia Journal of Mathematics, Science and Technology Education, vol. 4, no. 3, pp. 233-246, 2008.

[25] D. C. Jackson, The effect of concept mapping on preservice elementary teachers' knowledge of science inquiry teaching [Doctoral dissertation], Syracuse University, 2005.

[26] J. Machin, J. Varleys, and P. Loxley, "Exploring the use of concept chains to structure teacher trainees'understanding of science," International Journal of Science Education, vol. 26, no. 12, pp. 1445-1475, 2004.
[27] J. D. Novak and D. Musonda, "A twelve-year longitudinal study of science concept learning," American Educational Research Journal, vol. 28, pp. 117-153, 1991.

[28] W. R. Robinson, "A view from the science education research literature: concept map assessment of classroom learning," Journal of Chemical Education, vol. 76, no. 9, article 1179, 1999.

[29] K. Afamasaga-Fuata'i, "Students' conceptual understanding and critical thinking: a case for concept maps and vee-diagrams in mathematical problem solving," Australian Mathematics Teacher, vol. 64, no. 2, pp. 8-17, 2008.

[30] T. Steyn and A. Boer, "Mind mapping as a study tool for underprepared students in mathematics and science," South African Journal of Ethnology, vol. 21, no. 3, pp. 125-132, 1998.

[31] Y. Lee and D. W. Nelson, "Viewing or visualising-which concept map strategy works best on problem-solving performance?" British Journal of Educational Technology, vol. 36, no. 2, pp. 193-203, 2005.

[32] M. A. Ruiz-Primo, "Examining concept maps as an assessment tool," in Proceedings of the 1st International Conference on Concept Mapping, Pamplona, Spain, September 2004.

[33] R. McAleese, "Concept mapping-a critical review," Innovations in Education and Teaching International, vol. 36, no. 4, pp. 351360, 1999.

[34] B. Ferry, J. Hedberg, and B. Harper, "How do preservice teachers use concept maps to organize their curriculum content knowledge?" Journal of Interactive Learning Research, vol. 9, no. 1, pp. 83-104, 1998.

[35] J. C. Nesbit and O. O. Adesope, "Learning from animated concept maps with concurrent audio narration," Journal of Experimental Education, vol. 79, no. 2, pp. 209-230, 2011.

[36] C. De Simone, "Applications of concept mapping," College Teaching, vol. 55, no. 1, pp. 33-36, 2007.

[37] Elements and Principles of Design: Student Guide With Activities, Crystal Productions, Glenview, Ill, USA, 2000.

[38] M. Driscoll, "Psychological foundations of instructional design," in Trends and Issues in Instructional Design and Technology, R. Reiser and J. Dempsey, Eds., pp. 57-69, Pearson Education, Upper Saddle River, NJ, USA, 2002.

[39] R. Richey, The Theoretical and Conceptual Bases of Instructional Design, Nichols Publishing, New York, NY, USA, 1986.

[40] D. Ritchie and C. Volkl, "Effectiveness of two generative learning strategies in the science classroom," School Science \& Mathematics, vol. 100, no. 2, pp. 2-12, 2000.

[41] K. Y. Lim, H. W. Lee, and B. Grabowski, "Does conceptmapping strategy work for everyone? The levels of generativity and learners'self-regulated learning skills," British Journal of Educational Technology, vol. 40, no. 4, pp. 606-618, 2009.

[42] J. W. Berry and S. L. Chew, "Improving learning through interventions of student-generated questions and concept maps," Teaching of Psychology, vol. 35, no. 4, pp. 305-312, 2008. 

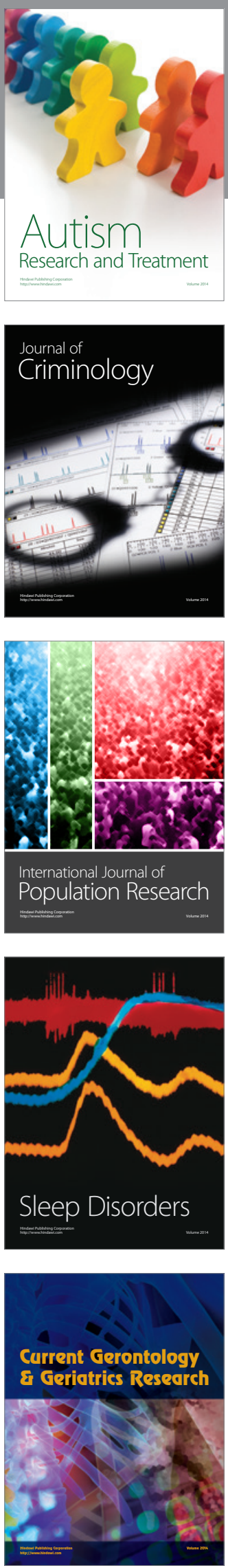
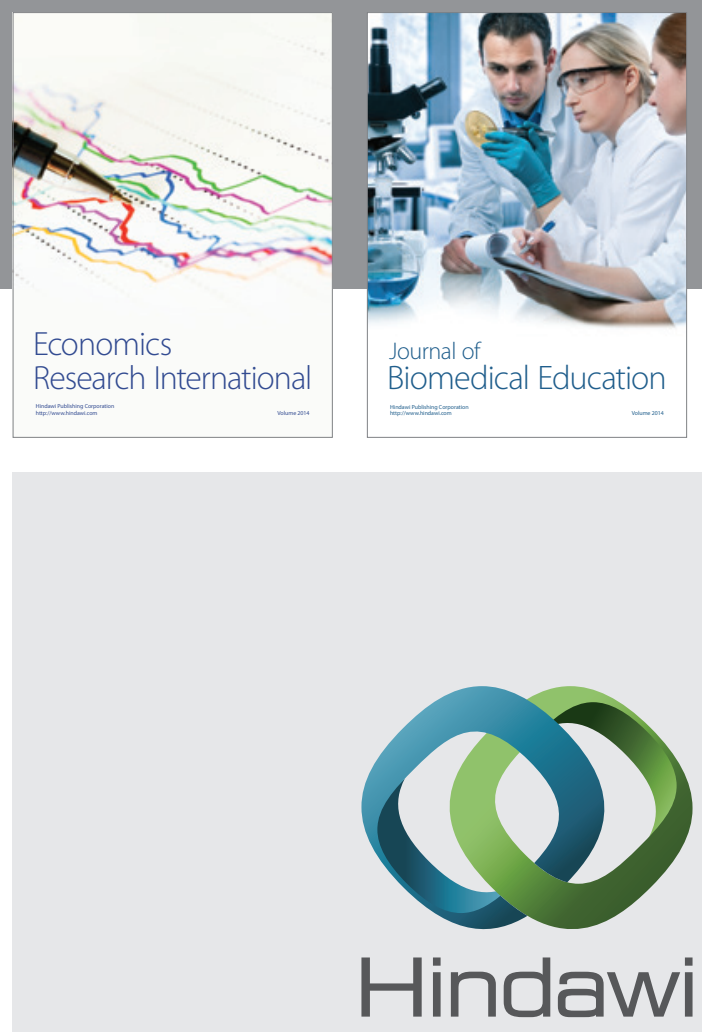

Submit your manuscripts at

http://www.hindawi.com
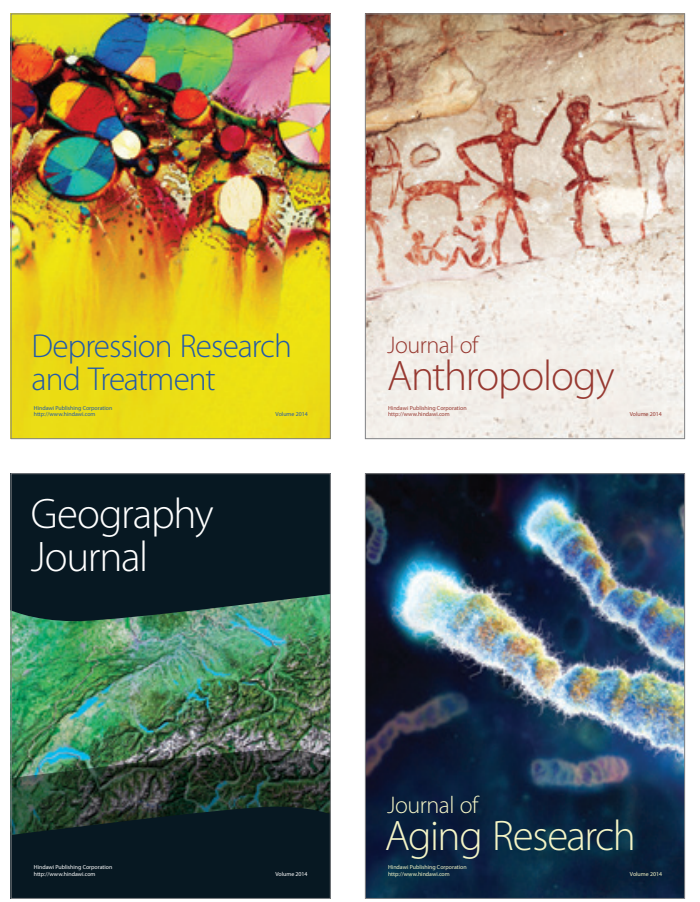
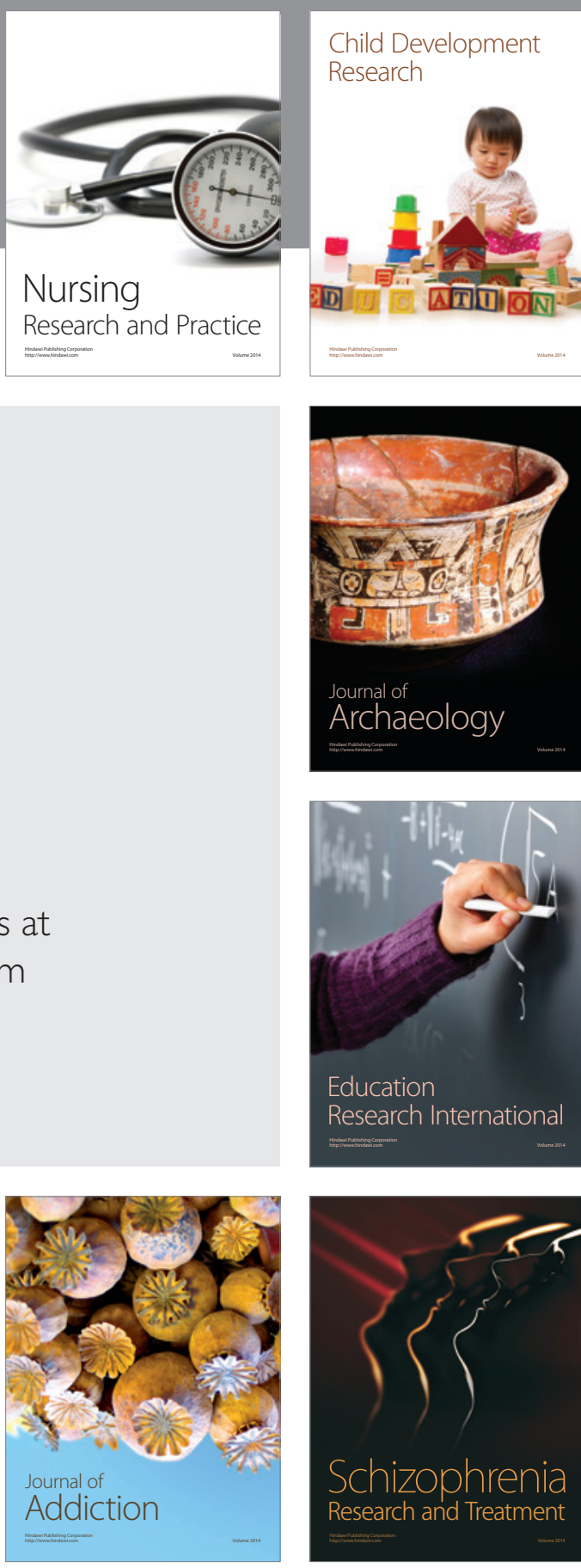

(D)
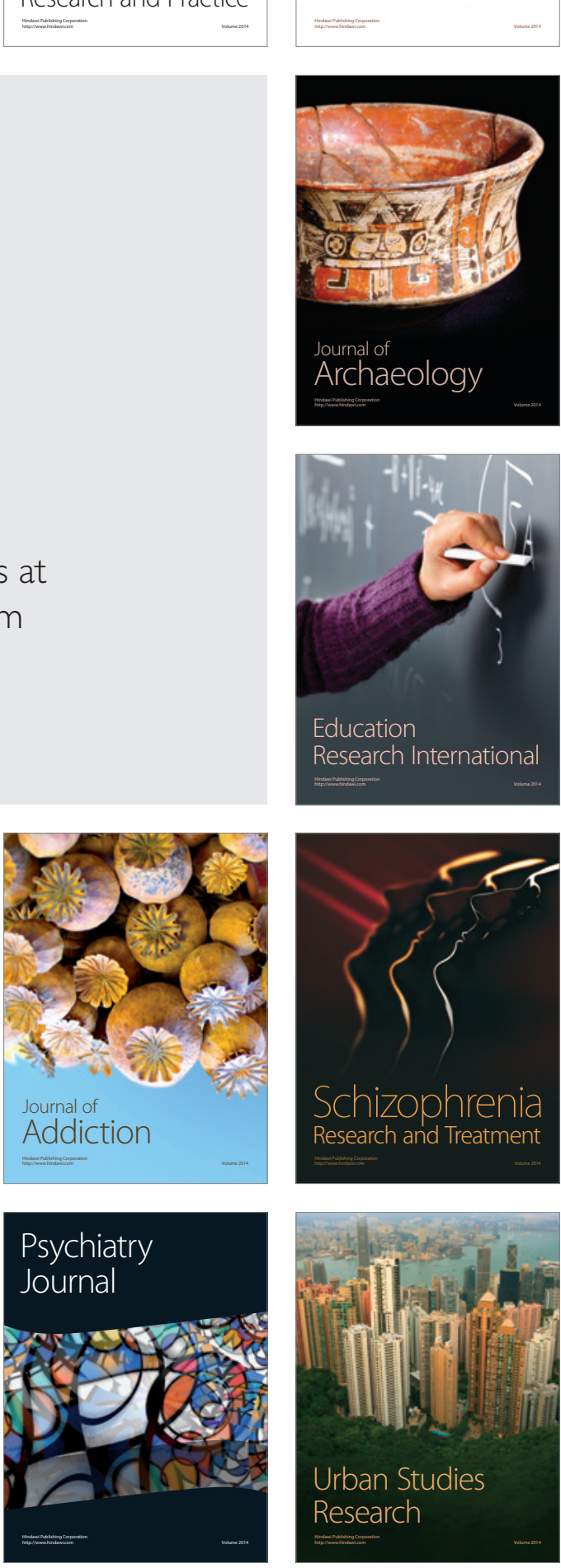